\title{
Endoscopic closure of lateral duodenal wall perforations caused by displacement of plastic biliary stents
}

We describe three patients with lateral duodenal wall perforations caused by the migration of plastic biliary stents after endoscopic retrograde cholangiopancreatography (ERCP)-guided biliary drainage.

The first patient was a 59-year-old man with a hilar lesion suspicious of a Bismuth IV cholangiocarcinoma, in whom a straight plastic stent $(8.5 \mathrm{Fr} \times 15 \mathrm{~cm})$ was placed in the left hepatic duct. He presented 24 hours later with diffuse abdominal pain due to stent migration and perforation of the third portion of the duodenum ( $\mathbf{F i g} \mathbf{1} \mathbf{a}$ ). After the stent had been removed with a foreign body biopsy forceps, closure was achieved with an over-the-scope clip (OTSC) (॰ Fig. 1 b).

The second patient was a 60-year-old man with Crohn's disease and a hilar lesion suspicious of a Bismuth IV cholangiocarcinoma, in whom a straight plastic stent $(10 \mathrm{Fr} \times 12 \mathrm{~cm})$ was placed. He presented 48 hours later with abdominal pain and systemic inflammatory response syndrome due to stent migration and perforation of the second portion of the duodenum ( $\mathbf{F i g} \mathbf{2} \mathbf{a}$ ). After stent removal, closure was achieved using a variation of the tulip bundle technique, with the placement of four through-thescope clips and a detachable snare beneath all the clips ( $\mathbf{F i g . 2} \mathbf{b}$ ).

Finally, we report the case of a 60-yearold man with liver cirrhosis who underwent ERCP because of biliary stones. After removal of the stones, a straight plastic stent $(10 \mathrm{Fr} \times 12 \mathrm{~cm})$ was placed because of the presence of a hilar stricture. He presented 2 months later with ascites and peritonitis due to stent migration and perforation of the second portion of the duodenum ( $>$ Fig.3). After stent removal, closure was achieved with the same variation of the tulip bundle technique ( $\triangleright$ Video 1$)$
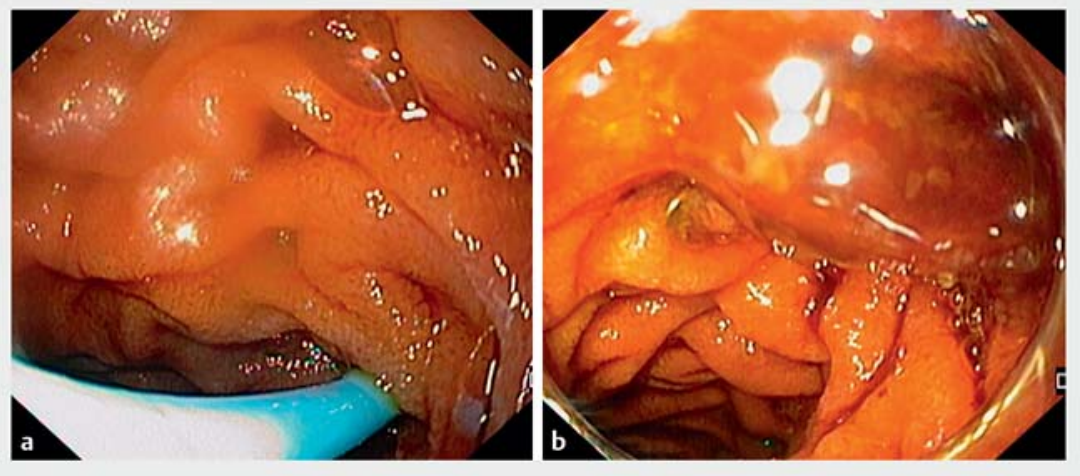

Fig. 1 Endoscopic images from patient \#1 showing: a a perforation of the duodenal wall by a plastic biliary stent; $\mathbf{b}$ the appearance after endoscopic closure with an over-the-scope clip.
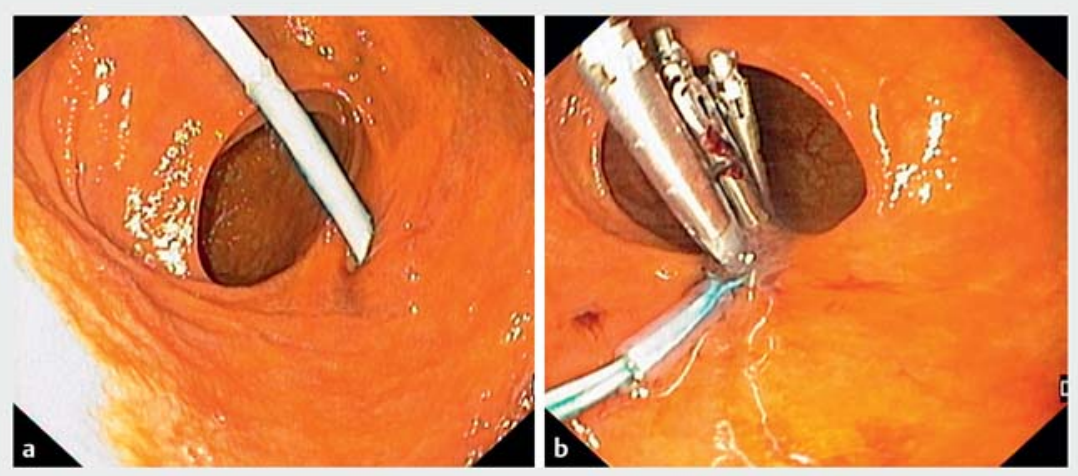

- Fig. 2 Endoscopic images from patient \#2 showing: a a duodenal wall perforation caused by a plastic biliary stent; $\mathbf{b}$ the appearance after endoscopic closure using a variation of the tulip bundle technique, with the placement of through-the-scope clips and a detachable snare beneath the clips.

No contrast extravasation was observed in any of the patients. After closure of the perforation, biliary drainage was achieved with nasobiliary tubes in all of the patients.

Duodenal wall perforation occurs in $1 \%$ of plastic stent migrations after biliary drainage [1]. The main causes of perforation have been reported to be the use of longer stents, stents being placed in the left intrahepatic duct, and delayed stent migration [2]. Endoscopy plays a major role in the management of this type of perforation, especially if it is diagnosed early.

Endoscopy_UCTN_Code_TTT_1AR_2AK

\section{Competing interests}

The authors declare that they have no conflict of interest. 


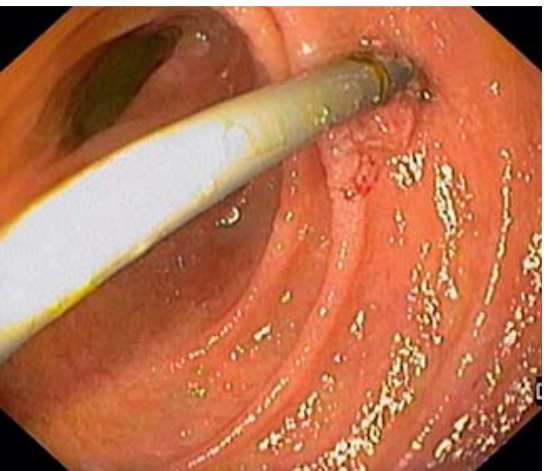

-Fig. 3 Endoscopic image from patient \#3 showing a duodenal wall perforation caused by a plastic biliary stent, which was subsequently closed with the same tulip bundle technique that was used for patient \#2.

The authors

Ana L. Santos, Eduardo Rodrigues-Pinto, Filipe Vilas-Boas, João Santos-Antunes, Pedro Pereira, Guilherme Macedo

Gastroenterology Department, Centro

Hospitalar São João, Porto, Portugal

Corresponding author

\section{Ana L. Santos, MD}

Gastroenterology Department, Centro

Hospitalar São João, Porto. Al. Prof. Hernâni Monteiro 4200, 319 Porto, Portugal

Fax: +351-22-5513601

anaasantos89@gmail.com
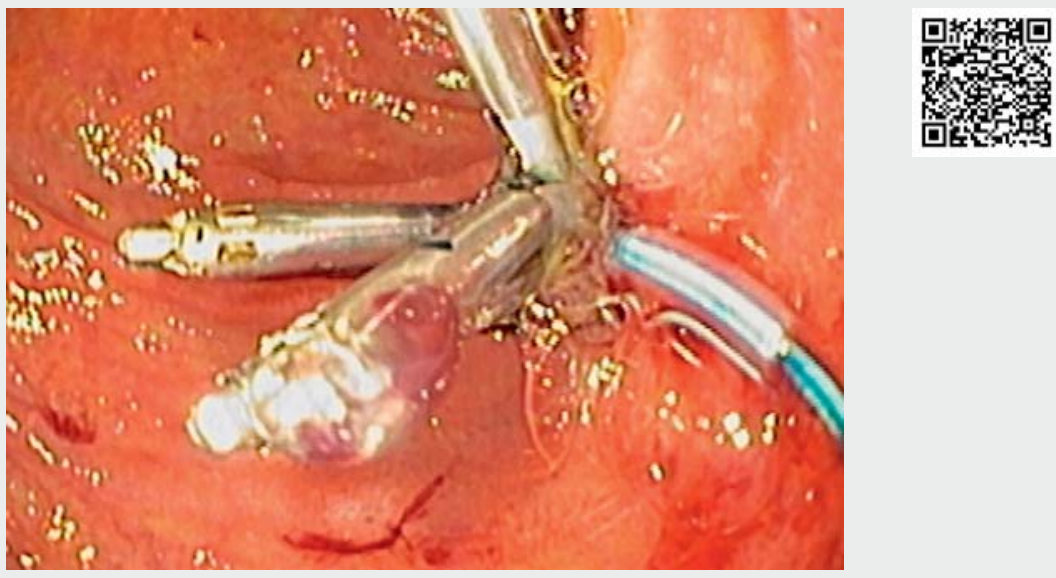

$\checkmark$ Video 1 Endoscopic closure of lateral duodenal wall perforations caused by displacement of plastic biliary stents in three patients.

\section{References}

[1] Jadallah K, Alzubi B, Sweidan A et al. Intraperitoneal duodenal perforation secondary to early migration of biliary stent: closure with through-the-scope clip. BMJ Case Rep 2019; 12: e230324

[2] Mangiavillano B, Pagano N, Baron TH et al. Biliary and pancreatic stenting: Devices and insertion techniques in therapeutic endoscopic retrograde cholangiopancreatography and endoscopic ultrasonography. World J Gastrointest Endosc 2016; 8: 143

\section{Bibliography}

DOI https://doi.org/10.1055/a-1119-0932

Published online: 27.3 .2020

Endoscopy 2020; 52: E357-E358

(c) Georg Thieme Verlag KG

Stuttgart · New York

ISSN 0013-726X

\section{ENDOSCOPY E-VIDEOS \\ https://eref.thieme.de/e-videos}

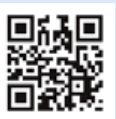

Endoscopy E-Videos is a free access online section, reporting on interesting cases and new techniques in gastroenterological endoscopy. All papers include a high quality video and all contributions are freely accessible online.

This section has its own submission website at https://mc.manuscriptcentral.com/e-videos 